\title{
What Lies Beneath: Exploring Different Depressive Symptoms Across Selected Risk Factors in Icelandic Team Sport Athletes
}

\author{
Richard Tahtinen \\ Liverpool John Moores University and \\ University of Akureyri \\ Daniel T. Olason \\ University of Iceland
}

Hafrun Kristjansdottir

Reykjavik University

\author{
Robert Morris \\ University of Stirling
}

\begin{abstract}
The aim of the study was to explore the prevalence of specific symptoms of depression in athletes and to test differences in the likelihood of athletes exhibiting these symptoms across age, sex, type of team sport, and level of competition. A sample of Icelandic male and female team sport athletes $(N=894,18-42$ years $)$ was included in the study. Of the athletes exhibiting clinically significant depressive symptoms on the Patient Health Questionnaire-9, 37.5\% did not exhibit core symptoms of depression. Compared with males, females were significantly more likely to exhibit depressed mood, feelings of worthlessness/guilt, and problems with sleep, fatigue, appetite, and concentration. Within males, differences were mostly related to neurovegetative aspects of depression (sleep and appetite), whereas in females, differences were related to cognitive/ emotional aspects (e.g., depressed mood, guilt/worthlessness). The findings underline the importance of exploring specific symptoms of depression to provide a richer understanding of depressive symptomology in athletes.
\end{abstract}

Keywords: assessment, Patient Health Questionnaire, prevalence, screening, sex differences

Within the past decade, depression-related research in athletes has aimed at establishing an improved understanding of athletes' susceptibility to depression and depressive symptoms (Golding, Gillingham, \& Perera, 2020; Gorczynski,

\footnotetext{
Tahtinen is with the School of Sport and Exercise Sciences, Liverpool John Moores University, Liverpool, United Kingdom; Tahtinen is also with the Faculty of Psychology, University of Akureyri, Akureyri, Iceland. Kristjansdottir is with the Department of Sport Sciences, Reykjavik University, Reykjavík, Iceland. Olason is with the Faculty of Psychology, University of Iceland, Reykjavík, Iceland. Morris is with the Faculty of Health Sciences and Sport, University of Stirling, Scotland, United Kingdom. Tahtinen (richard@unak.is) is corresponding author.
} 
Coyle, \& Gibson, 2017; Wolanin, Gross, \& Hong, 2015). There is now an empirically grounded consensus that athletes are a unique population challenged by a range of generic and sport-specific stressors (Küttel \& Larsen, 2019; Reardon et al., 2019; Wolanin et al., 2015) and that prevalence rates of depressive symptoms in athletes may be comparable with those observed in the general population (Gorczynski et al., 2017; Junge \& Feddermann-Demont, 2016; Nixdorf, Hautzinger, \& Beckmann, 2013; Wolanin, Hong, Marks, Panchoo, \& Gross, 2016). As reported in a recent review by Golding et al. (2020), depressive symptom prevalence has ranged from $6.7 \%$ to $34.0 \%$ across athlete samples, and several demographic risk factors such as sex, level of competition, and type of sport have been linked with elevated depressive symptoms in this population. Similar to research on normative sex differences (Breslau et al., 2017; Hankin et al., 1998), female athletes have been shown to report higher levels of depressive symptoms than male athletes (Gorczynski et al., 2017; Wolanin et al., 2015). It has also been suggested that athletes competing at lower levels exhibit a higher prevalence of depressive symptoms than those competing at higher levels (Junge \& Prinz, 2019; Nixdorf et al., 2013). However, younger age has also been shown to correlate with elevated depressive symptoms in athletes (Beable, Fulcher, Lee, \& Hamilton, 2017), and it is therefore uncertain whether the observed difference between higher- and lower-level athletes is due to the level of competition per se or whether this relationship is better explained by potential age effects. Recent evidence has also shown that susceptibility to depression and depressive symptoms may vary across different types of sports (Schaal et al., 2011; Wolanin et al., 2016). However, as discussed by several authors (e.g. Nixdorf et al., 2013; Tahtinen et al., 2020; Wolanin et al., 2016), samples have often consisted of a relatively small number of athletes across different sports, and therefore, comparisons have tended to focus on differences between broader sport categories, such as team and individual sports (e.g., Beable et al., 2017; Nixdorf et al., 2013). Consequently, to better understand potential sport-specific differences, scholars have underlined that future studies should aim to include larger samples across specific sports (Golding et al., 2020; Junge \& Feddermann-Demont, 2016; Junge \& Prinz, 2019; Nixdorf et al., 2013; Wolanin et al., 2016).

Although the evidence based on various depression-related topics in athletes has been growing rapidly, less attention has, however, been paid to the heterogeneous subset of symptoms that underlie the construct of depression itself (Ringland, 2016; Schuch, 2015) and the potential implications this heterogeneity may have on the interpretation and dissemination of research findings (Golding et al., 2020; Schuch, 2015). Therefore, we will briefly discuss the definition and assessment of depression and how the current study aims to address these issues.

According to the Diagnostic and Statistical Manual of Mental Disorders (DSM-5; American Psychiatric Association, 2013), major depressive disorder (MDD) is defined as consisting of nine potential symptoms: depressed mood, decreased interest or pleasure (anhedonia), changes in weight or appetite, problems with sleep, psychomotor agitation or retardation, fatigue/loss of energy, worthlessness/guilt, problems with concentration, and thoughts of death. MDD is diagnosed by structured or semistructured clinical interviews, and to receive a diagnosis, individuals must exhibit five (or more) depressive symptoms of which at least one must be depressed mood or decreased interest/pleasure (American Psychiatric Association, 2013). Considering that depressed mood or decreased interest/pleasure is the only specified symptom required for a diagnosis, the 
symptom presentation across individuals diagnosed with MDD can be highly heterogeneous (individuals exhibit different types of symptoms; Zimmerman, Ellison, Young, Chelminski, \& Dalrymple, 2015). There are, in fact “ . . roughly 1,000 unique combinations of symptoms that all qualify for a diagnosis of MDD, some of which do not share a single symptom" (Fried \& Nesse, 2015b, p.2)

Depression can also be assessed via self-report questionnaires in which the overall symptom severity, rather than a formal diagnosis, is the main outcome measure (Fried \& Nesse, 2015b; Ingram, Siegle, \& Steidtmann, 2015). Questionnaires can vary in terms of their assessment period (e.g., symptoms present for the past week or past 2 weeks) and the number and type of symptoms assessed. For example, the Center for Epidemiologic Studies Depression Scale (Radloff, 1977) is a 20-item questionnaire and assesses the presence of both positive and negative affect items in the past week. Another commonly utilized self-report measure (Golding et al., 2020; Trojian, 2016) is the nine-item Patient Health Questionnaire (PHQ-9, Kroenke \& Spitzer, 2002), which is specifically designed to assess the presence of the nine depressive symptoms listed in DSM over the past 2 weeks. Despite the structural differences of depression questionnaires or screening tools, a common feature is that the overall symptom severity is calculated by summing scores from individual symptom items. Specified cutoff points are then imposed to indicate the clinical significance of symptom severity, that is, whether the summed scores reach severity levels that may call for intervention or further assessment (Kroenke \& Spitzer, 2002; Radloff, 1977). However, when summed symptom scores are utilized to determine clinical significance, there is no criterion for the type or number of symptoms that must be present (Fried et al., 2016). Consequently, the symptom heterogeneity discussed concerning MDD is further escalated when depression is operationalized in terms of summed symptom scores (Fried et al., 2016).

Although questionnaires have been the most common method of assessment in depression-related research in athletes (Golding et al., 2020), studies sometimes identify this method as a limitation of their study-highlighting that questionnaires do not provide a diagnosis of depression (e.g., Beable et al., 2017; Weber et al., 2018). However, if questionnaires are not designed to diagnose depression (Levis et al., 2020), then identifying them as a limitation in this context may convey a paradoxical message-implicitly suggesting that, in essence, the objective of the research is to estimate the prevalence of MDD. When this is coupled with the interchangeable use of the terms depression and depressive symptoms, there is an increased risk that sum scores on questionnaires become interpreted as a proxy for MDD (Schuch, 2015). This would be problematic, however, considering that clinically significant scores identified by questionnaires could be acquired in the absence of the core symptoms of depression and that clinically significant sum scores do not require the presence of any specified number of symptoms (Fried \& Nesse, 2015a). Consequently, on some screening tools, such as the PHQ-9, it would be plausible for an athlete to report an elevated score merely on a single symptom and still receive a clinically significant sum score. In fact, clinically significant scores could be attained by athletes who would not fulfill a single criterion for a diagnosis of MDD if assessment were performed via clinical interviews. Indeed, recent findings suggest that screening tools such as the PHQ-9 significantly overestimate rates of MDD (Levis et al., 2020).

Considering the heterogeneity of depressive symptoms, there is also an inherent disadvantage in interpreting questionnaire data solely in relation to sum 
scores, as they may mask important information of the underlying symptomology (Fried, Nesse, Zivin, Guille, \& Sen, 2014; Ingram et al., 2015; Moriarity \& Alloy, 2020). Consequently, the interpretation of findings could, in some cases, turn out to be ". . as inadequate as the count of broken bones in a trauma victim" (Fried \& Nesse, 2015a, pp., 6-7). This is, however, not to mean that sum scores should not be applied or that they are not meaningful in research or practice but, rather, that there may be several opportunities over and beyond sum scores that symptom-based assessment could offer. For example, although elevated depressive symptoms have shown to increase the risk of developing MDD over time (Ingram et al., 2015), experiencing issues with a specific depressive symptom, such as problems with sleep, can in itself be a significant source of distress and impairment for athletes (Moesch et al., 2018; Reardon et al., 2019; Roberts, Faull, \& Tod, 2016). Depressive symptoms may also vary in their impact on individuals' psychosocial functioning and can differ in their salience across different life domains (e.g., work and interpersonal relationships; Fried et al., 2016; Fried \& Nesse, 2014). There is also evidence suggesting that depressive symptoms may be differentially related to risk factors. Lux and Kendler (2010), for example, observed that in a sample of individuals diagnosed with MDD, females were more likely to exhibit depressed mood, appetite/weight changes, and fatigue, whereas males were more likely to exhibit psychomotor agitation/retardation. Furthermore, elevated symptoms of depressed mood and psychomotor agitation/retardation were related to older age.

Despite the recent developments in research on depressive symptom prevalence and associated risk factors in athletes (Golding et al., 2020; Moesch et al., 2018; Reardon et al., 2019; Wolanin et al., 2015), to our knowledge, previous studies have not explored the prevalence of the specific symptoms that lie beneath summed symptom scores. We propose that exploring specific symptoms in addition to sum scores offers an opportunity for establishing a richer understanding of the underlying issues that may be relevant in athletes. Exploring specific symptomology may also be especially fruitful as this "may enable the development of personalized prevention that focuses on specific problems and symptoms before they transition into a fullfledged depressive episode" (Fried \& Nesse, 2015b, p.4). Against this backdrop, in this preliminary investigation, we first aim to complement previous research by reporting the overall prevalence rates of depressive symptoms and compare these across age, sex, type of team sport, and level of competition. We also aim to extend current symptom-based research by: (a) exploring the prevalence of the core symptoms of depression (i.e., depressed mood and lack of interest/pleasure) across different sum score severity and by identifying the number of additional symptoms exhibited by athletes with or without these core symptoms, and (b) by testing potential differences in the likelihood of exhibiting specific depressive symptoms across age, sex, type of team sport, and level of competition.

\section{Methods}

\section{Participants}

The data for the current study were derived from a project exploring gambling behaviors in Icelandic athletes competing in football, basketball, and handball. Of the estimated population of Icelandic competitive adult athletes in these sports 
$(N=3,641)$, a total of 1,241 athletes $(34.1 \%)$ participated in the research project. For the current study, however, only athletes with valid responses to one or more depressive symptom items were included. Therefore, of the 1,241 participants, 894 athletes $(72.0 \%$ ) were included in the current study (football $=63.2 \%$; basketball $=$ $100 \%$; handball $=70.5 \%$ ). More specifically, the current sample for football represented $20.3 \%$ of the Icelandic adult football population $(N=2,170$ across 105 teams) with a total of 441 participants included (age range 18-41 years, male $70.1 \%$ ). For basketball, the sample represented $36.1 \%$ of the Icelandic adult basketball population ( $N=659$ across 56 teams) with a total of 238 participants (age range 18-41 years, male 62.6\%). For handball, the sample represented 26.5\% of the Icelandic adult handball population ( $N=812$ across 20 teams) with a total of 215 participants (age range 18-42 years, male 51.2\%).

\section{Measures}

Depressive symptoms were assessed by the PHQ-9 (Kroenke \& Spitzer, 2002), which assesses the presence of the nine depressive symptoms listed in DSM during the past 2 weeks: "little interest or pleasure doing things" (interest), "feeling down, depressed, or hopeless" (depressed mood), "trouble falling or staying asleep, or sleeping too much" (sleep), "feeling tired or having little energy" (fatigue), "poor appetite or overeating" (appetite), "feeling bad about yourself—or that you are a failure or have let yourself or your family down" (worthlessness/guilt), "trouble concentrating on things, such as reading the newspaper or watching television" (concentration), "moving or speaking so slowly that other people could have noticed? Or the opposite- being so fidgety or restless that you have been moving around a lot more than usual" (psychomotor), and "thoughts that you would be better off dead or of hurting yourself in some way" (suicidal thoughts; Kroenke \& Spitzer, 2002). Each item is scored on a range from 0 to 3, where $0=$ "not at all," $1=$ "several days," 2 = "more than half the days," and $3=$ "nearly every day," with sum scores ranging from 0 to 27. Kroenke and Spitzer (2002) suggested a cutoff score of $\geq 10$ (at least moderate severity) for identifying individuals with clinically relevant symptoms. However, it has also been noted that it is important to report prevalence rates using different cutoff points to offer more valid comparisons across studies (Manea, Gilbody, \& McMillan, 2012). Considering the exploratory nature of the current study, we report the prevalence of clinically significant symptoms utilizing cutoffs $\geq 10$ (at least moderate symptoms) and $\geq 15$ (at least moderately severe symptoms; Kroenke \& Spitzer, 2002). Furthermore, the PHQ-9 scores can also be analyzed using an algorithm method. As described by Manea, Gilbody, and McMillan (2015), when using the algorithm method, clinical significance is determined based on the DSM criteria where at least five symptoms must be present (item scored $\geq 2$ except for suicidal ideation, scored $\geq 1)^{1}$ of which at least one must be depressed mood or lack of interest/anhedonia. The algorithm method has low sensitivity (increased risk for false negatives) but shows excellent specificity (decreased likelihood of false positives), whereas the sum score method has shown to have more optimal trade-off between sensitivity and specificity (Manea et al., 2015). As the goal of questionnaires (or screening tools) is to overestimate true rates to minimize potential false-negative cases (failing to identify cases with the condition), the sum score method has been more commonly 
utilized (Manea et al., 2015). However, as the aim of this study is to explore the underlying symptomology in more detail, we also explore prevalence rates using the algorithm method. The psychometric properties of PHQ-9 have been shown to be good among the clinical (Kroenke \& Spitzer, 2002) and the general populations (Martin, Rief, Klaiberg, \& Braehler, 2006), including the Icelandic population (Pálsdóttir, 2007). The internal consistency of the scale in the current sample was $\alpha=.86$.

\section{Procedure}

In collaboration with the Icelandic national associations in football (Knattspyrnusamband Íslands, KSÍ), basketball (Körfuknattleikssamband Íslands), and handball (Handknattleikssamband Íslands, HSÍ), the general managers of all clubs in Iceland were contacted and requested to participate and to cooperate in recruiting gatekeepers (coaches) from their respective clubs. Only one football club declined the invitation to participate in the study. Following approval for cooperation, a link to the questionnaire was sent to the gatekeepers within every team who, then, shared the link with their players (age $\geq 18$ ) and encouraged them to participate in the study. Gatekeepers were contacted approximately 2-3 weeks following the initial contact, requesting them to remind the players about the study. All potential participants were informed that participation in the study was optional, responses on the questionnaire were anonymous, and that they could withdraw from the study at any point. Participants were also provided with contact information for psychological support and encouraged to seek help if they were experiencing any type of distress. Participants did not receive any form of compensation for their participation. Permission for the study was obtained from the National Bioethics Committee in Iceland (B20171100004 and S1512-00001) and the Icelandic Data Protection Authority.

\section{Statistical Analyses}

We utilized logistic regression models with adjusted odds ratios and 95\% confidence intervals (CIs) to test differences across two generic (sex and age) and two sport-specific (level of competition and type of team sport) variables on the odds of exhibiting specific depressive symptoms.

Binary-dependent variables (specific symptoms) were coded as " 0 " = not present and " $1 "=$ present. For eight symptoms, the score of $\geq 2$ ("more than half the days" or "nearly every day" in the past two weeks) signified the presence of the symptom; however, for "suicidal thoughts," a score of $\geq 1$ (at least "several days") implied the presence of the symptom (Lux \& Kendler, 2010; Manea et al., 2015). We coded predictors as binary dummy variables with the reference category coded as " 0 " and each remaining level within the predictor as " 1 ." Each level (" 1 ") was then tested separately against the reference category (" 0 "). The reference category was assumed to exhibit the lowest levels of depressive symptoms. The reference categories across predictive variables were male (sex), older (age), and top level (level of competition). As previous literature has not explored differences across the specific sports included in our study, football (type of team sport) was chosen as the reference group (lowest mean sum score). Due to a low number of 
female athletes 27 and older, the older female group (reference category) included ages $\geq 24$, whereas for males, the reference group consisted of athletes $\geq 27$ years old.

The regression models for comparing male and female athletes across specific symptoms were adjusted for age, type of sport, and level of competition, whereas the models comparing different sports were adjusted for sex, age, and level of competition. Analyses on sex differences within athletes with clinically significant scores (PHQ-9 $\geq 10$ ) were, however, unadjusted due to the low number of athletes in this subgroup $(n=72)$. Models testing differences across age and level of competition were conducted separately for male and female athletes, adjusting for the remaining predictors.

Two participants had one missing value on the PHQ-9 scale (case 1, response on sleep missing and case 2 , response on concentration missing) but were included in the sum score analyses by replacing the missing value with 0 (symptom not present). Results for sum score and logistic regression analyses were tested with and without this correction, and there were no notable differences in the outcome. Nine other cases had more than one missing item on the PHQ-9 scale and were, therefore, not included in the sum score analyses. However, all cases with valid responses to specific items were included in the logistic regression analyses across specific symptoms. All analyses were conducted using the IBM SPSS version 25.0 (Armonk, NY).

\section{Results}

\section{Sum Score Means and Prevalence Across Determinants}

The overall prevalence of clinically significant depressive symptoms in the sample $(N=885)$ was $8.1 \%$ and $2.7 \%$ when applying a cutoff score $\geq 10$ and $\geq 15$, respectively. As shown in Table 1, the corresponding prevalence rates when applying cutoffs $\geq 10$ and $\geq 15$ were $5.8 \%$ and $2.3 \%$ for male athletes $(N=565)$ and $12.2 \%$ and $3.4 \%$ for female athletes $(N=320)$. The Kruskall-Wallis test showed that female athletes had a significantly higher prevalence than male athletes when cutoff score 10 was applied $[H(1)=11.00, p=.001]$; however, no significant difference was observed when cutoff 15 was applied. In female athletes, Kruskall-Wallis test showed that prevalence (cutoff 10) was significantly different between age groups $[\mathrm{H}(4)=11.55$, $p=.02$ ], with 18 - to 20-year-olds having a significantly higher prevalence rate $(19 \%)$ than 21 - to 23 -year-olds $(8.3 \%, p=.02)$, 24- to 26-year-olds $(6.3 \%, p=.20)$, and 27 to 29 -year-olds $(3.8 \%, p=.03)$. When applying the cutoff score of 15 , no significant differences were observed in female athletes across the predictive variables. Independent of the cutoff score used, there were no significant differences in prevalence rates across the predictive variables in male athletes.

As also shown in Table 1, female athletes had significantly higher mean symptom scores $(M=5.11, S D=4.38)$ than male athletes $(M=3.05, S D=3.70)$ $[t(575.17)=-7.10, p<.001]$. In male athletes, the only mean depressive symptom score difference was found between type of sports, $F(2,562)=4.04, p=.018$, with Tukey post hoc test revealing a significantly higher score for male handball players $(M=3.93, S D=3.82)$ than football players $(M=2.77, S D=3.35 ; p=.013)$. In female athletes, the only significant difference was found across age, $F$ (4, $315)=3.90, p=.004$, and according to Tukey post hoc test, this difference was 


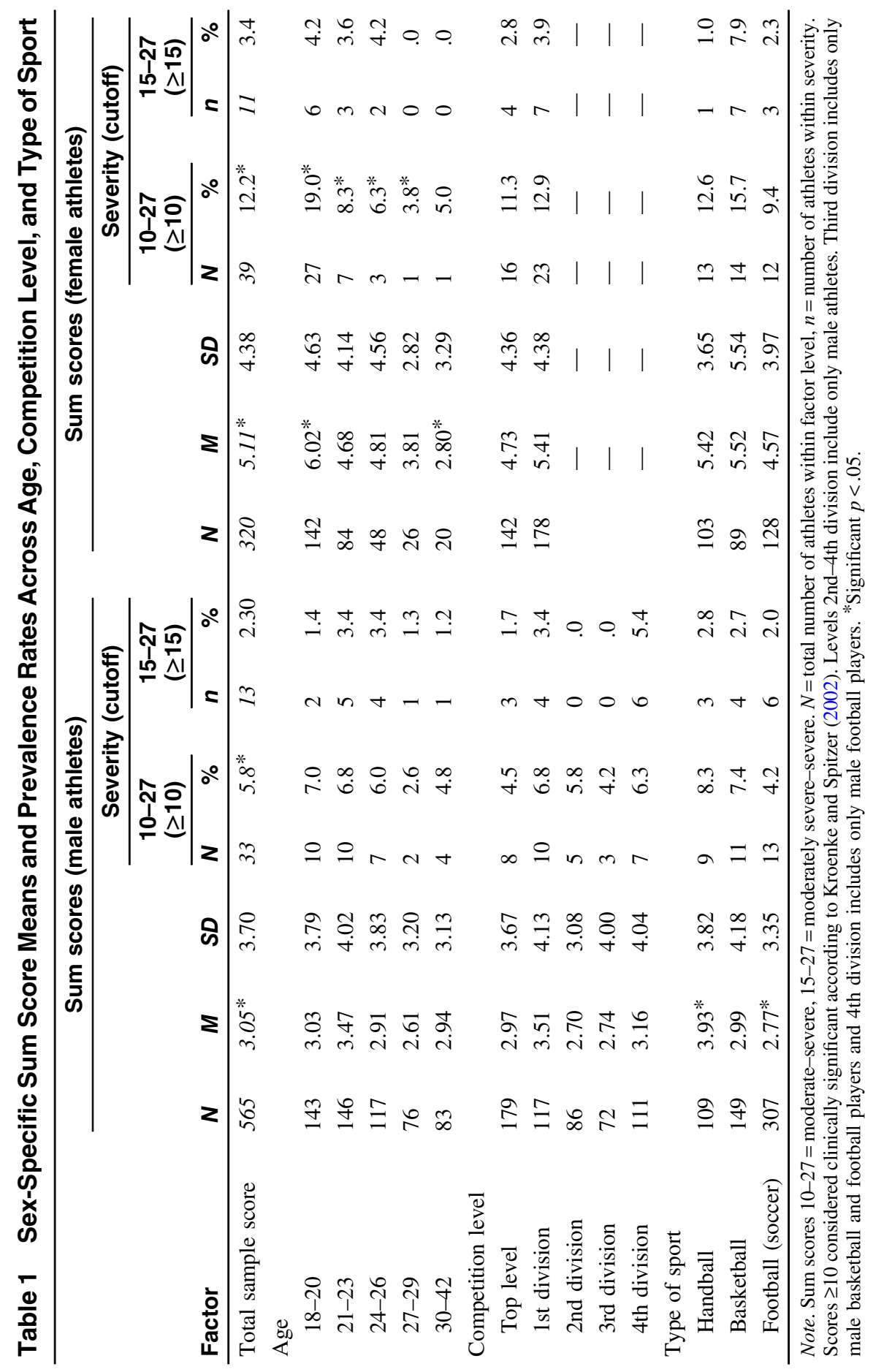


significant between the youngest (18- to 20-year-old, $M=6.02, S D=4.63$ ) and oldest athletes (30- to 42-year-old, $M=2.80, S D=3.29 ; p=.004$ ).

\section{Prevalence of Specific and Total Number of Symptoms}

Table 2 shows the overall prevalence of the specific depressive symptoms in the sample and among athletes with and without clinically significant sum scores. Prevalence of specific symptoms for the whole sample ranged from $1.6 \%$ for suicidal ideation to $12.2 \%$ for fatigue. The core symptoms of depression, lack of interest and depressed mood, were present for most of the days in the past 2 weeks in $6.8 \%$ and $5.9 \%$ of the sample, respectively. Approximately half of the athletes with clinically significant sum scores exhibited the core symptoms of depression. In terms of the total number of symptoms (Table 2), $75.7 \%$ of the sample did not exhibit any symptoms and $16.3 \%$ exhibited one to two symptoms. Within athletes who had clinically significant sum scores, $51.4 \%$ reported three to four and $38.9 \%$ reported five or more symptoms.

\section{Table 2 Prevalence of Individual Depressive Symptoms for the Sample and for Athletes With and Without Clinically Significant Sum Scores}

\begin{tabular}{|c|c|c|c|c|}
\hline \multirow[b]{3}{*}{ Factor } & \multirow{3}{*}{$\begin{array}{c}\begin{array}{c}\text { Total } \\
\text { sample }\end{array} \\
N / n\end{array}$} & \multirow[b]{3}{*}{$\%$} & $\begin{array}{l}\text { Symptom sum } \\
\text { score }\end{array}$ & \multirow{3}{*}{$\begin{array}{c}\begin{array}{c}\geq 10 \\
(N=72)\end{array} \\
\%\end{array}$} \\
\hline & & & \multirow{2}{*}{$\frac{\leq 9(N=813)}{\%}$} & \\
\hline & & & & \\
\hline \multicolumn{5}{|l|}{ Type of symptom } \\
\hline Lack of interest & $894 / 61$ & 6.8 & 2.3 & 55.6 \\
\hline Depressed mood & $892 / 53$ & 5.9 & 1.6 & 51.4 \\
\hline Sleep problems & $894 / 71$ & 7.9 & 3.9 & 51.4 \\
\hline Fatigue & $894 / 109$ & 12.2 & 6.9 & 66.7 \\
\hline $\begin{array}{l}\text { Problems with } \\
\text { appetite }\end{array}$ & $894 / 62$ & 6.9 & 2.0 & 59.7 \\
\hline Worthlessness/guilt & $894 / 76$ & 8.5 & 3.4 & 63.9 \\
\hline $\begin{array}{l}\text { Concentration } \\
\text { problems }\end{array}$ & $894 / 58$ & 6.5 & 2.5 & 50.0 \\
\hline $\begin{array}{l}\text { Psychomotor } \\
\text { problems }\end{array}$ & $892 / 26$ & 2.9 & 1.0 & 23.6 \\
\hline Suicidal thoughts & $888 / 14$ & 1.6 & .0 & 19.4 \\
\hline \multicolumn{5}{|l|}{ Number of symptoms } \\
\hline None & $885 / 670$ & 75.7 & 82.4 & .0 \\
\hline $1-2$ & $885 / 144$ & 16.3 & 16.9 & 9.7 \\
\hline $3-4$ & $885 / 43$ & 4.9 & .7 & 51.4 \\
\hline$\geq 5$ & $885 / 28$ & 3.2 & .0 & 38.9 \\
\hline
\end{tabular}




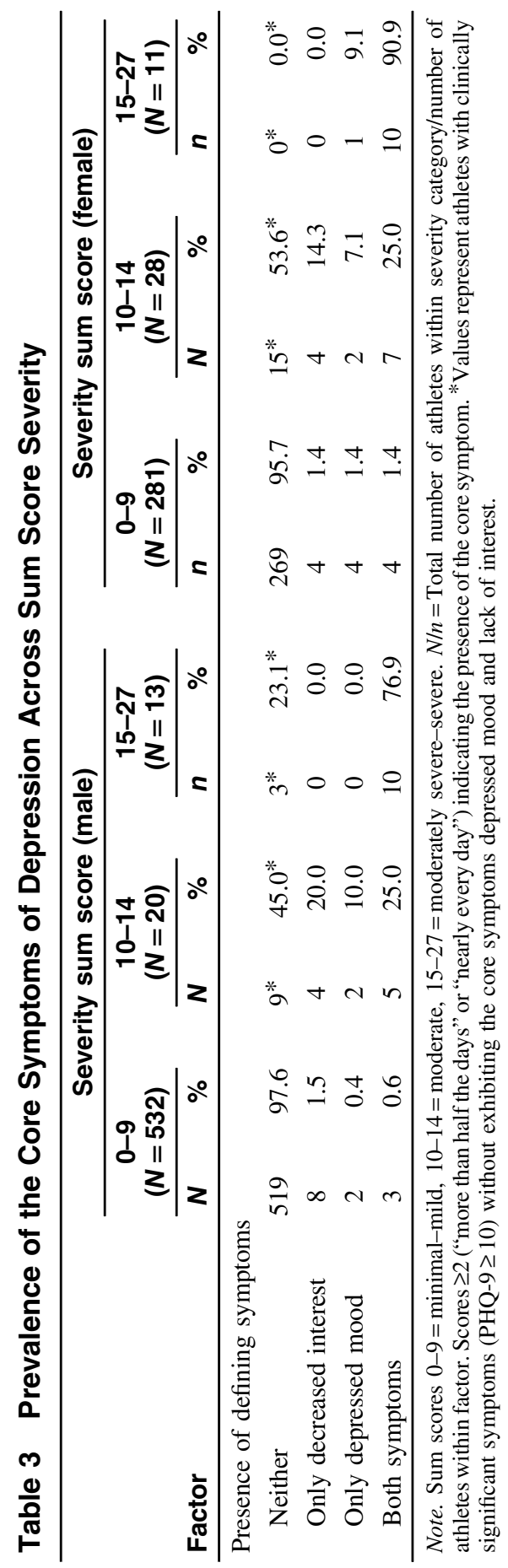




\section{Prevalence of Core Symptoms of Depression Across Sum Score Severity}

Table 3 illustrates the prevalence of the core symptoms (i.e., depressed mood and lack of interest/pleasure) across athletes with different sum score severity. Of the male athletes with PHQ-9 sum scores in the 10-14 range (moderate depressive symptoms, $n=20$ ), $45 \%$ did not exhibit either of the core symptoms of depression. Of the male athletes with PHQ-9 scores in the 15-27 range (moderately severe to severe symptoms, $n=13$ ), $23.1 \%$ did not exhibit the core symptoms. In females, $53.6 \%$ of athletes within the $10-14$ range $(n=28)$ did not exhibit the core symptoms, whereas all female athletes within the 15-27 range $(n=11)$ exhibited at least one of the core symptoms. Overall, 37.5\% (27/72) of all athletes with clinically significant sum scores (PHQ-9 $\geq 10$ ) did not exhibit the core symptoms of depression. However, when the PHQ-9 cutoff $\geq 15$ was applied, only $12.5 \%(3 / 24)$ of athletes with clinically significant scores did not exhibit the core symptoms.

\section{Number of Additional Symptoms Across Athletes With and Without Core Symptoms of Depression}

The total number of additional symptoms across athletes with or without the core symptoms of depression is presented in Table 4. Of the athletes that did not exhibit the core symptoms of depression $(n=813)$, the vast majority exhibited no other depressive symptoms $(82.4 \%)$ or one to two symptoms $(15.1 \%)$. Of those athletes that presented only lack of interest $(n=20)$ or only depressed mood $(n=11)$, two athletes $(6.5 \%)$ exhibited four additional symptoms. Of the athletes presenting with both core symptoms of depression $(n=39), 61.5 \%$ exhibited three or more

\section{Table 4 Number of Additional Symptoms Across Athletes Without and With the Core Symptoms of Depression}

\begin{tabular}{|c|c|c|c|c|c|c|c|c|c|c|}
\hline \multirow[b]{3}{*}{ Factor } & \multicolumn{10}{|c|}{$\begin{array}{l}\text { Number of additional symptoms (excluding } \\
\text { decreased interest and depressed mood) }\end{array}$} \\
\hline & \multicolumn{2}{|c|}{0} & \multicolumn{2}{|c|}{1} & \multicolumn{2}{|c|}{2} & \multicolumn{2}{|r|}{3} & \multicolumn{2}{|c|}{$\geq 4$} \\
\hline & $N$ & $\%$ & $N$ & $\%$ & $n$ & $\%$ & $N$ & $\%$ & $n$ & $\%$ \\
\hline \multicolumn{11}{|l|}{$\begin{array}{l}\text { Presence of defining } \\
\text { symptoms }\end{array}$} \\
\hline Neither $(N=815)$ & 670 & 82.4 & 96 & 11.8 & 28 & 3.4 & 14 & 1.7 & 7 & 0.9 \\
\hline $\begin{array}{l}\text { Only decreased } \\
\text { interest }(N=20)\end{array}$ & 7 & 35.0 & 5 & 25.0 & 3 & 15.0 & 4 & 20.0 & $1^{*}$ & $5.0^{*}$ \\
\hline $\begin{array}{l}\text { Only depressed mood } \\
(N=11)\end{array}$ & 1 & 9.1 & 4 & 36.4 & 4 & 36.4 & 1 & 9.1 & $1^{*}$ & $9.1^{*}$ \\
\hline $\begin{array}{l}\text { Both symptoms } \\
(N=39)\end{array}$ & 3 & 7.7 & 4 & 10.3 & 8 & 20.5 & $6^{*}$ & $15.4^{*}$ & $18^{*}$ & $46.2^{*}$ \\
\hline
\end{tabular}

Note. $N / n=$ Total number of athletes within factor/frequency of athletes exhibiting number of symptoms. Scores $\geq 2$ ("more than half the days" or "nearly every day") indicating the presence of a symptom (for suicidal ideation scores $\geq 1$ "several days" or higher indicated presence). *Values identified as clinically significant based on the algorithm method (Manea et al., 2015). 
additional symptoms. Hence, overall, $2.9 \%(n=26)$ of athletes exhibited a total of five symptoms of which at least one was either depressed mood or lack of interest.

\section{Differences in the Odds of Experiencing Specific Depressive Symptoms Across Selected Determinants}

Table 5 shows adjusted logistic regression models for each depressive symptom across the selected determinants. Compared with male athletes, female athletes were significantly more likely to report depressed mood, sleep problems, fatigue, problems relating to appetite, feelings of worthlessness/guilt, and problems with concentration (controlling for the effects of age, level of competition, and type of sport). The highest odds for females in comparison with males were found in fatigue $(\mathrm{OR}=3.88,95 \%$ CI $[2.37,6.37])$, depressed $\operatorname{mood}(\mathrm{OR}=2.08,95 \%$ CI $[1.91,3.97])$, and appetite-related issues $(\mathrm{OR}=2.08,95 \% \mathrm{CI}[1.15,3.74])$. When sex differences were explored among athletes with clinically significant sum scores (PHQ-9 $\geq 10$; not included in Table 5), female athletes showed significantly higher odds of fatigue $(\mathrm{OR}=6.60,95 \% \mathrm{CI}[2.18,19.97])$, however, females showed significantly lower odds of psychomotor issues than males $(\mathrm{OR}=.26,95 \% \mathrm{CI}[0.08,0.84])$.

When football players were compared with players from the two other team sports, handball players had significantly higher odds of experiencing depressed mood and issues with sleep and appetite, whereas basketball players showed higher odds of sleep and appetite-related issues than football players (adjusting for sex, age, and level of competition). Most notably, the likelihood of experiencing appetiterelated issues more than half the days in the past 2 weeks was more than fourfold $(\mathrm{OR}=4.31,95 \% \mathrm{CI}[2.03,9.18])$ in basketball players than in football players.

Due to sex differences in the distribution of scores in age and level of competition, these variables were explored separately for male and female athletes. Models for age were adjusted for level of competition and type of sport, and models for the level of competition were adjusted for type of sport and age. As shown in Table 5, when male athletes 27 years and older were compared with the other age groups, 21- to 23- and 18- to 20-year-olds had significantly higher odds of exhibiting depressed mood and issues with sleep and appetite. Odds of experiencing issues with appetite were notably high with 21 - to 23 -year-olds showing almost fivefold $(\mathrm{OR}=4.90,95 \% \mathrm{CI}[1.01,23.90])$ and 18 - to 20-year-olds sevenfold increase in odds $(\mathrm{OR}=7.06,95 \%$ CI $[1.52,32.79])$ when compared with male athletes 27 years and older. Furthermore, male athletes aged 18 to 20 years showed significantly higher odds of experiencing lack of interest than male athletes aged 27 years and older. Within female athletes, 18- to 20-year-olds showed significantly higher odds of exhibiting the core symptoms of depression (lack of interest and depressed mood) than female athletes aged 24 years and older. Female athletes aged 18 to 20 years old also had a higher likelihood of feeling worthlessness/guilt and having problems with concentration. In these comparisons, the most notable difference was found in the likelihood of experiencing depressed mood with the youngest female athletes having an almost fivefold increase in odds $(\mathrm{OR}=4.78$, 95\% CI $[1.37,16.65])$ compared with female athletes aged 24 years and older.

Concerning the level of competition, the only differences were observed between male top-level and male first-division players. Male athletes competing in first division (second-highest level) had significantly higher odds of experiencing 


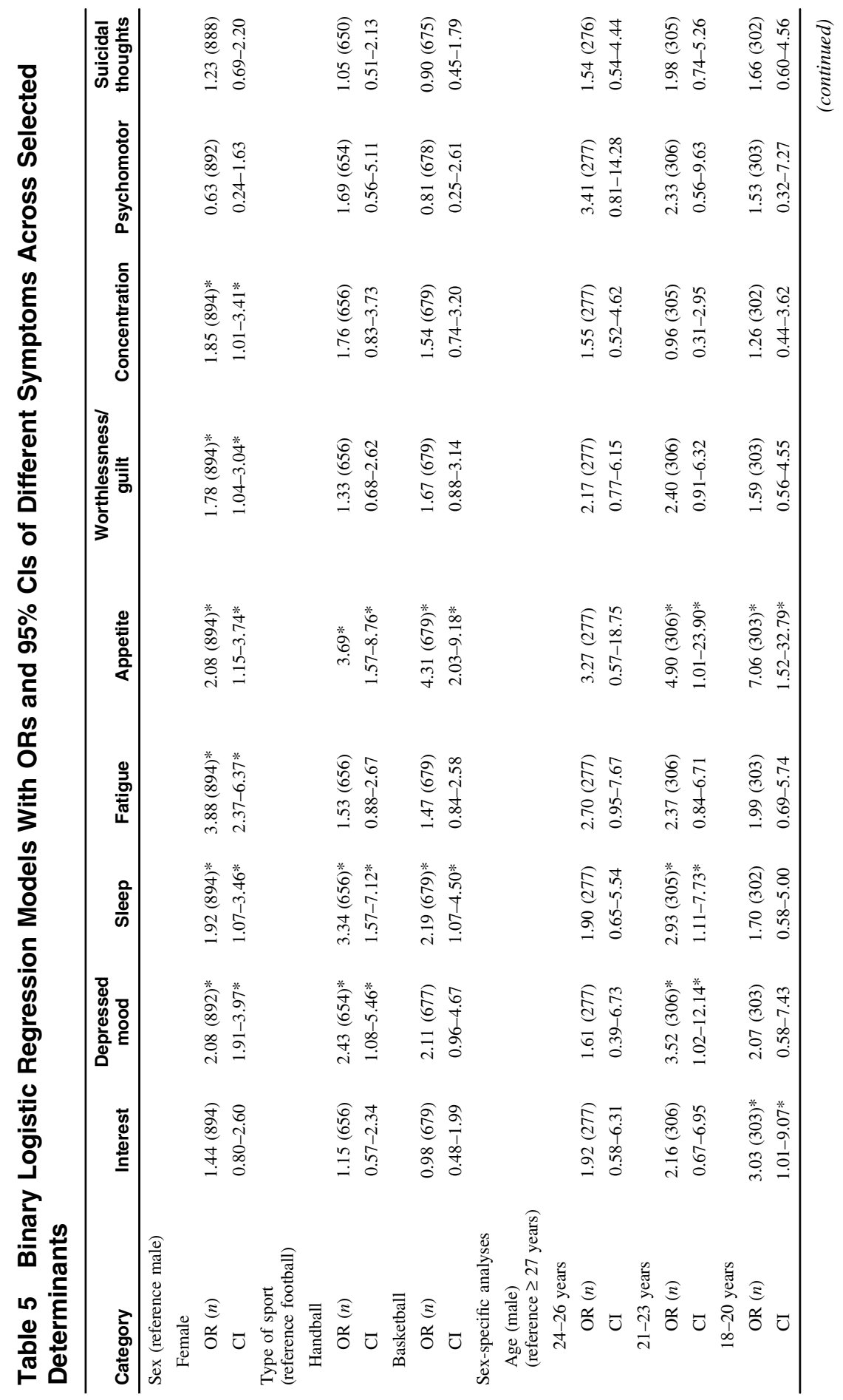




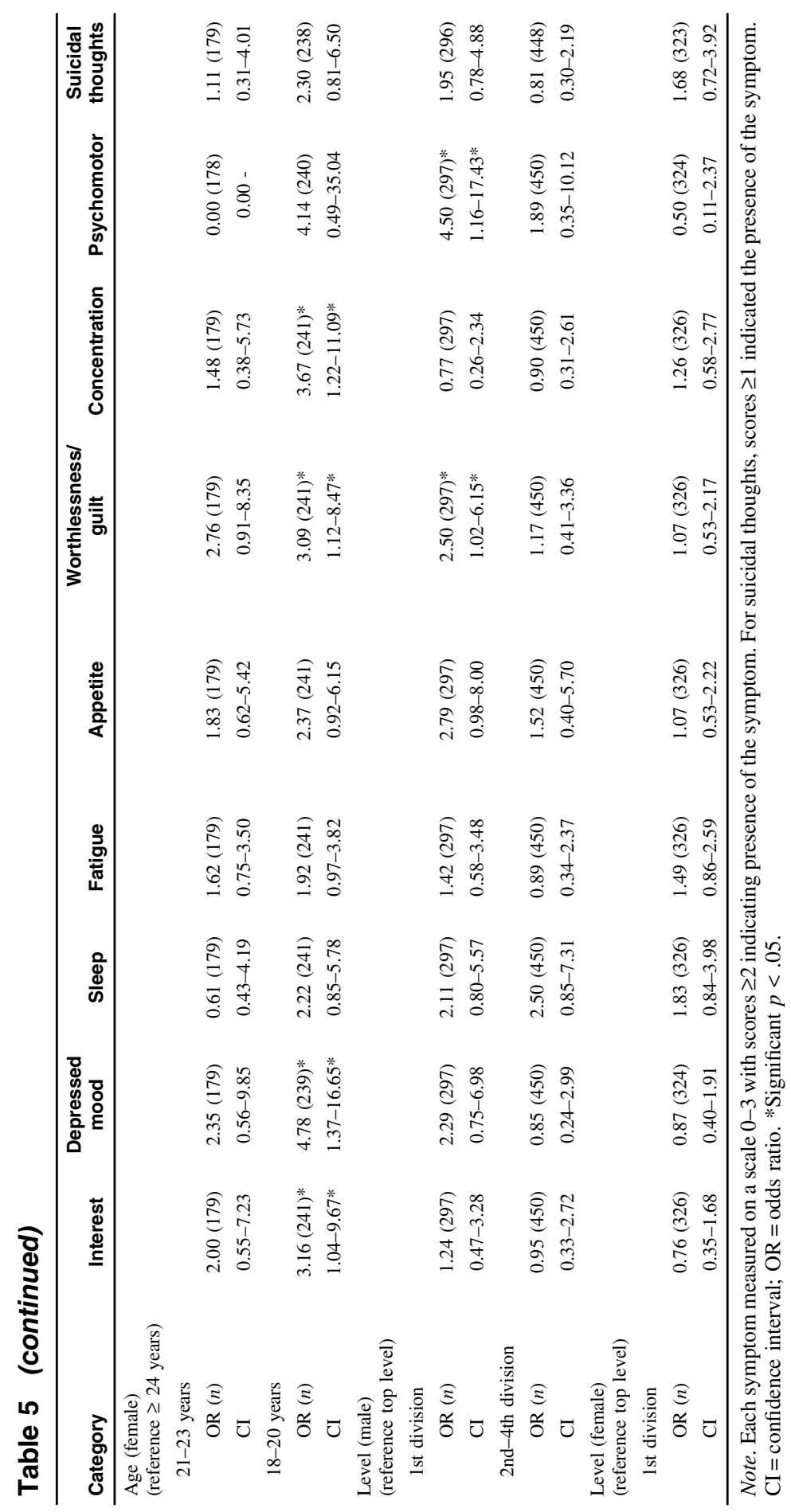


worthlessness/guilt and psychomotor issues than top-level players. Most notably, first-division players had more than a fourfold increase in odds $(\mathrm{OR}=4.50,95 \% \mathrm{CI}$ $[1.16,17.43])$ of experiencing psychomotor issues when compared with top-level players.

\section{Discussion}

In this preliminary investigation, we aimed to complement previous research by exploring the overall prevalence of depressive symptoms and to test potential differences across generic and sport-specific determinants in a large representative sample of Icelandic team sport athletes. Additionally, to further extend knowledge advancement in the field, we explored the prevalence of specific depressive symptoms and tested potential within factor differences (e.g., different age groups) in the odds of experiencing different types of depressive symptoms.

\section{Sum Score Means and Prevalence Across Determinants}

The overall prevalence of depressive symptoms in the sample was $8.1 \%$ and $2.7 \%$ when applying a cutoff score of $\geq 10$ and $\geq 15$, respectively. In comparison, Tahtinen and Kristjansdottir (2019) reported a $20.9 \%$ prevalence rate in Icelandic individual sport athletes using the PHQ-9 with a cutoff score of 10. This supports some previous findings that have suggested that elevated depressive symptoms may be more prevalent in individual sport athletes when compared with team sport athletes (Beable et al., 2017; Nixdorf et al., 2013, Nixdorf, Frank \& Beckmann, 2016). Female athletes in our sample had a significantly higher prevalence of depressive symptoms than male athletes when a cutoff score of 10 was applied, which is in line with previous findings on sex differences in athletes (Golding et al., 2020). However, no sex differences were observed when applying a cutoff score of 15 , suggesting that although female athletes may be more likely than males to experience moderate levels of depressive symptoms, the rates of more severe symptomology may be comparable between the sexes. Within female athletes, the only significant mean differences emerged between younger and older athletes, and in male athletes, the only difference was found between different sports. This latter finding is somewhat surprising considering that football, handball, and basketball are all team ball sports in which the nature of competition (e.g., team-based with competition outcome evaluated objectively, i.e., scoring points/goals) and related stressors, such as public evaluation of performance (Doherty, Hannigan, \& Campbell, 2016), could be expected to be somewhat similar. We did not, however, assess other factors that could have explained the observed differences, such as injury or concussion (Rice et al., 2016), overtraining (Peluso \& Andrade, 2005), or burnout (Gerber et al., 2018), which have all shown to relate to higher depressive symptoms. Nevertheless, our findings highlight that although the broader sports categories such as individual and team sports have shown to differ in rates of depressive symptoms (Beable et al., 2017; Nixdorf et al., 2016), there may also be important differences across different sports within these broader categories (Rice et al., 2016). In line with recent research (Golding et al., 2020; Junge \& FeddermannDemont, 2016; Junge \& Prinz, 2019; Nixdorf et al., 2013; Wolanin et al., 2016), our 
study emphasizes the need for more fine-grained analyses across different sports to better understand factors that may contribute to elevated depressive symptoms in athletes.

\section{Prevalence of Specific Symptomology}

In the current sample, the prevalence of specific depressive symptoms (symptoms present at least most of the days in the past 2 weeks) ranged from $1.6 \%$ for suicidal ideation to $12.2 \%$ for fatigue. As shown in our data and previous research, fatigue (low energy/tiredness) is a common symptom in athletes (Birrer, Lienhard, Williams, Röthlin, \& Morgan, 2013; Matos, Winsley, \& Williams, 2011) and could, therefore, represent an important target for future prevention programs independent of the type of athletes the program is designed for.

As most studies to date have utilized questionnaires to assess depression in athletes, current knowledge of athletes' susceptibility to MDD is largely unknown (for a notable exception see Schaal et al., 2011). Nonetheless, research in athletes has tended to utilize the terms depression and depressive symptoms interchangeably when discussing clinically significant depressive symptom sum scores, potentially clouding the meaning and interpretation of findings across studies (Schuch, 2015). One of the aims of this study was, therefore, to explore sum scores from the perspective of DSM criteria. Several studies in athletes have utilized PHQ-9 scores $\geq 10$ as a cutoff for identifying clinically relevant cases and reporting prevalence rates (Bell et al., 2016; Du Preez et al., 2017; McGuire, Ingram, Sachs, \& Tierney, 2017; Silva-Rocha, de Sousa, \& Osório, 2019; Tahtinen et al., 2020; Tahtinen \& Kristjansdottir, 2019). We, however, speculated that when applying this cutoff, athletes could attain clinically significant scores without exhibiting the core symptoms of depression (i.e., lack of interest and depressed mood). Indeed, we found that $37.5 \%$ of all athletes who had clinically significant sum scores (PHQ-9 $\geq 10$ ) did not exhibit the core symptoms of depression. However, this was reduced to $12.5 \%$ among athletes with moderately severe to severe sum scores (PHQ-9 $\geq 15$ ). Furthermore, $45 \%$ of male and $53.6 \%$ of female athletes with moderate depressive symptoms (PHQ-9 scores 10-14) did not exhibit the core symptoms of depression. According to Kroenke, Spitzer, and Williams (2001), the PHQ-9 shows increasing specificity (decrease in potential false-positive cases) but attenuated sensitivity (increase in potential false-negative cases) as cutoff scores increase in the moderate depressive symptom range (scores 10-14), and hence, this range has also been identified as the "grey zone." Considering that approximately half of the athletes scoring within the "grey zone" did not exhibit the core symptoms of depression-it could have been deemed misleading to define athletes with clinically significant symptom scores in the 10-14 range as "depressed" athletes. On the other hand, using a higher cutoff point could potentially lead to an increased risk of missing "true" cases. Although we did not conduct diagnostic interviews to test the sensitivity and specificity of the PHQ-9 scale in our athlete sample, our findings provide new insights into the underlying symptomology in athletes with clinically significant sum scores.

We also speculated that it would be plausible for an athlete to report an elevated score merely on a single symptom and still receive a clinically significant sum score. However, $90 \%$ of athletes who had clinically significant depressive symptoms exhibited at least three symptoms. To further understand clinically 
significant symptoms in our sample, we applied an algorithm method to explore the number of athletes that self-reportedly fulfilled the DSM criteria for exhibiting a minimum of five symptoms, of which at least one symptom was either depressed mood or lack of interest. We found that, overall, $2.9 \%$ of athletes self-reported meeting these criteria, which is considerably lower than the $8.1 \%$ prevalence observed when cutoff score 10 was applied and closer to the prevalence rate obtained by cutoff score $15(2.7 \%)$. This is also similar to the $3.6 \%$ prevalence reported in a study among French elite athletes who were assessed using semistructured diagnostic interviews (Schaal et al., 2011). We only know of one study to date that has reported prevalence rates in athletes using both selfreport questionnaires and clinical interviews. In their study, Hammond, Gialloreto, Kubas, and Hap Davis (2013) found that 34\% of elite swimmers met DSM criteria for a major depressive episode when assessed by clinical consultations, whereas $22 \%$ reported mild and only $4 \%$ moderate levels of depressive symptoms when assessed by the Beck's Depression Inventory-II. Considering that screening tools are designed to overestimate true cases (Manea et al., 2015), finding a higher number of cases by clinical interviews than questionnaires is surprising. It has, however, been underlined that the optimal cutoff score may depend on the setting in which assessment is conducted, that is, the same cutoff score can result in many false positives in one setting while leading to more false negatives in another (Manea et al., 2012). Hence, considering the findings in the current study and those reported by Hammond et al. (2013), future studies are needed to validate existing screening tools in the athlete populations.

\section{Differences in the Odds of Experiencing Specific Depressive Symptoms Across Selected Determinants}

When compared with male athletes, female athletes showed significantly higher odds of exhibiting depressed mood, sleep problems, fatigue, problems relating to appetite, feelings of worthlessness/guilt, and problems with concentration. Furthermore, we found that among athletes with clinically significant sum scores, females were more likely than males to experience fatigue, whereas males were more likely to experience psychomotor issues. Our findings are in line with those reported by Lux and Kendler (2010), where females diagnosed with MDD were more likely than males to exhibit depressed mood, appetite/weight changes, and fatigue, whereas males were more likely to experience psychomotor issues. Our symptom-specific analyses extend current knowledge and suggest that the higher overall depressive symptom severity identified in females is reflected in several specific symptoms. It is interesting to note, however, that while the key symptoms differing within the male sample were related to neurovegetative symptoms (sleep and appetite), within female athletes, variability was more prominent in cognitive symptoms. For example, when compared with older female athletes, the youngest female athletes in our sample had significantly higher odds of exhibiting a lack of interest, depressed mood, and worthlessness/guilt as well as concentration problems. Most notably, younger female athletes (18-20 years) had almost a fivefold increase in odds of experiencing depressed mood compared with female athletes aged 24 years and older. Relatively few studies in athletes have, however, explored depression or other mental health issues specifically in female athletes (Golding et al., 2020; Küttel \& Larsen, 2019). Considering that female 
athletes exhibited higher prevalence rates across several specific symptoms when compared with male athletes, attention in future research, prevention, and applied efforts should be directed at this population. Furthermore, although sex differences have been noted in previous research, there is a gap in our knowledge concerning the factors that could potentially explain these differences. In this context, and as has been voiced by Nixdorf, Beckmann, and Nixdorf (2020), future research could benefit from exploring cognitive mechanisms and environmental stressors to identify factors that may be especially relevant for targeted prevention and treatment among at-risk athletes.

Although our sum score analyses identified overall differences between football players and handball players, symptom-specific analyses revealed additional findings. Both handball and basketball players were more likely to report issues with sleep and appetite in comparison to football players. Also, handball players were more likely than football players to report experiencing depressed mood. Depressed mood and issues with sleep and appetite were also the key symptoms in males when age differences were compared between older and younger athletes. The odds of experiencing issues with appetite were notably high with 21- to 23-year-old males showing almost a fivefold increase and 18- to 20-year-olds a sevenfold increase in odds compared with male athletes aged 27 years or older. Although it is difficult to speculate as to why we found these differences, regulation of sleep and appetite has shown to be related to similar biomarkers among depressed patients (Caroleo et al., 2019). Based on our findings, these specific symptoms could provide an interesting avenue for further research in depression-related research in athletes.

Level of competition did not contribute to differences across depressive symptoms within female athletes. Considering that our adjusted analyses demonstrated more variability across age than level of competition, the higher susceptibility of lower level athletes found in previous studies (Junge \& Feddermann-Demont, 2016; Junge \& Prinz, 2019; Nixdorf et al., 2013) may be better explained by age-related differences. Nevertheless, while controlling for the effects of age and type of sport, we found that male athletes competing in first division (second-highest level) had significantly higher odds of experiencing worthlessness/guilt and psychomotor issues than top-level players. Although the findings concerning differences in psychomotor issues may be difficult to interpret, the observed difference in worthlessness/guilt could, perhaps, be understood through the lens of athletic identity (Brewer \& Petitpas, 2017). As there may be similar physical and psychosocial demands (e.g., training and competition load) for first-division and top-league players in Iceland, a strong identification with the athlete role may be comparable between these groups. However, the threats to athletic identity may be more pronounced for the first-division players as the sport career prospects may be less secure than for the top-level players.

Overall, our exploratory findings highlight the importance of applying an analysis of the underlying symptomology in parallel to reporting sum scores when assessing depressive symptoms in athletes. If findings are interpreted only in terms of summed scores, important information may be lost and interpretations may have limited utility in terms of knowledge advancement in the field. Applying a more detailed exploration of the underlying symptomology could also generate useful information for more theory-driven approaches to understanding depression and depressive symptoms in athletes and, therefore, the development of more targeted and tailor-made approaches to intervention in the future (Nixdorf et al., 2020). As noted 
by Purcell, Gwyther, and Rice (2019), it is also important to understand athlete mental health from a broader ecological perspective. We propose that exploring individual symptoms rather than only sum scores could significantly contribute to this understanding in future research. For example, by providing more detailed information about the specific symptoms that may be especially prevalent in different athlete populations, future research could more systematically map the relevant contextual risk factors that may contribute to these symptoms.

\section{Clinical Implications}

Service provision for athletes can vary largely across different sport settings (Kroshus, 2016; Moesch et al., 2018). In Iceland (as in many other countries; Moesch et al., 2018), there are currently no systematic protocols in place for the assessment or treatment of mental health issues in athletes. However, as the current and previous findings (e.g., Kristjánsdóttir, Sigurðardóttir, Jónsdóttir, Porsteinsdóttir, \& Saavedra, 2019; Tahtinen \& Kristjansdottir, 2019) suggest, more systematic approaches to providing mental health support among the Icelandic athlete population may be warranted.

Although systematic screening of depressive symptoms has been highlighted as an important objective for identifying and supporting at-risk athletes (Donohue et al., 2019; Wolanin et al., 2016), "routine" screening has also been questioned. Notably, the potentially high number of false-positive cases identified by screening tools could lead to adverse consequences, such as overdiagnosis of depression and increased risk of labeling and stigma among individuals screened with elevated symptom scores (He et al., 2020; Joffres et al., 2013; Mojtabai, 2017). This may be especially relevant in athletes considering that screening tools have not yet been properly validated in this population (Moesch et al., 2018). As shown in our study, although $90 \%$ of athletes with clinically significant sum scores exhibited at least three different depressive symptoms, approximately $50 \%$ of athletes with moderate symptom severity (clinically significant score 10-14) did not exhibit the core symptoms of depression (depressed mood and lack of interest).

If systematic screening is conducted in settings where there is already a suitable support infrastructure in place, it is important to determine which screening tool(s) and cutoff score(s) are utilized to identify athletes for a follow-up (Trojian, 2016). Considering that screening tools are designed to overestimate "true" clinical cases to minimize potential false-negative cases-rather than merely "red-flagging" athletes with clinically significant depressive symptom scores-exploring the specific symptomology could potentially improve the specificity of the screening results. For example, analyzing scores specifically for symptoms such as depressed mood and/or lack of interest, insomnia, or suicidal thoughts may be important when considering further follow-up (Joffres et al., 2013). Furthermore, it is important to determine how initial screening results are communicated to athletes and that athletes are included in the process when determining potential mental health referrals (Donohue et al., 2018; Joffres et al., 2013; Trojian, 2016). Considering our findings, discussing specific symptoms and related issues that are especially relevant for athletes could potentially improve this decision-making process.

As shown in a study by Kroshus (2016), there was, on average, one full-time physician for each NCAA division I sports medicine department and 376.4 student 
athletes per physician. Applying the $23.7 \%$ prevalence rate reported in college athletes by Wolanin et al. (2016) and the average number of students per physician reported by Kroshus (2016), at any given time there would be approximately 89 NCAA division I collegiate athletes per physician screened with clinically significant depressive symptoms. This underlines the importance of conducting an evidence-based assessment of the target population and the resources required to assure that appropriate follow-up assessment and mental health support can be provided to athletes following the screening process. It must, however, be noted that our aim with this discussion is not to recommend for or against screening in athletes but to highlight the potential utility of exploring individual depressive symptoms in settings where screening protocols are being planned or already in place.

In our sample, 17\% $(n=138)$ of athletes with nonclinically significant depressive symptom sum scores reported experiencing one to two depressive symptoms most of the days in the past 2 weeks. It is, therefore, important for practitioners working with athletes to be mindful of the possibility that although an athlete does not present with clinically significant depressive symptom sum scores, they may, nevertheless, experience significant distress and impairment in specific areas of functioning (e.g., issues with sleep/appetite, feelings of guilt). Therefore, independent of the sum scores, it may be beneficial to discuss with the athlete about the individual symptoms on which they may exhibit elevated scores. This could also open new doors to identifying other potential mental health issues (Mummery, 2005; Trojian, 2016). For example, there is considerable overlap between symptoms of depression and other conditions highly relevant in the athlete population, such as overtraining syndrome (Kreher, 2016), burnout (Nixdorf et al., 2020), and eating disorders (Kristjánsdóttir et al., 2019), and hence, a detailed analysis of the specific symptomology may provide the practitioner with additional road signs when conceptualizing potential issues that may need further assessment.

One of the interesting and perhaps surprising findings in our study was that there were significant differences in the mean sum scores and the prevalence of specific symptoms between the three team sports included in our study. This suggests that even across sports that could be considered similar in terms of the nature of the competition (e.g., team based with competition outcome evaluated objectively, i.e., scoring points/goals), there may be important contextual differences influencing athletes' mental health (Rice et al., 2016). Therefore, practitioners working in teambased settings could benefit from exploring specific symptoms to gain clues to the potential contextual factors that could undermine athletes' well-being and performance. For example, if issues with sleep seem to be highly prevalent in the team or within the organization, the practitioner could map potential risk factors (e.g., training times, logistic issues in relation to traveling, etc.) and consequently plan targeted interventions to address these issues.

\section{Limitations and Future Directions}

Some limitations to the current study should be noted. First, the mean difference analyses did not consider potential differences emanating from unmeasured third variables, and therefore, these unadjusted mean differences should be interpreted with this limitation in mind. This study was also cross-sectional and can only be 
considered descriptive of prevalence at one point in time. There is now evidence suggesting that prevalence rates may vary over a competitive season (Du Preez et al., 2017; McGuire et al., 2017), and hence, the reported rates should not be considered static. Furthermore, although we had large sample sizes across the included sports, almost $40 \%$ of football players and $30 \%$ of handball players did not respond to the depression symptom items and were, therefore, excluded from the current study. Consequently, the representativeness of our findings should be interpreted with this limitation in mind. In terms of our logistic regression analyses, the overall rates for some symptoms (e.g., psychomotor) were low, which may have biased the odds ratio estimates. Furthermore, it should be noted that several of the PHQ-9 items do not make a distinction between the direction of symptom presentation (e.g., eating too little or overeating, sleeping too much/too little). Hence, we were not able to identify the exact nature of the issues relating to these symptoms.

Despite the limitations, our study offers an important addition to previous depression-related research in athletes. We utilized a large representative sample of team sport athletes from three popular team sports in Iceland. We also had sufficiently large subsamples across the different sport and nonsport-specific determinants, allowing us to conduct more specific (adjusted) analyses across these determinants. Our approach to exploring the prevalence of specific depressive symptoms was also novel in the athlete literature. Future research could take our analyses further and explore how different symptoms may relate to athlete functioning, in and out of sport, and explore these relations within prospective research designs. For example, in nonathletes, sad mood and concentration difficulties have been shown to have the most severe influence on overall psychosocial functioning, whereas insomnia had a strong influence on work life, self-blame on close relationships, and loss of interest on social activities (Fried \& Nesse, 2014).

\section{Conclusions}

Although research in athletes often notes that depression questionnaires are limited in their ability to provide a depression diagnosis, few have explored the opportunities that questionnaires can offer over and beyond the more commonly utilized sum scores. As our study shows, there is a wealth of information to be gleaned by analyzing the specific symptoms of depression. The initial findings suggest that female athletes report more symptoms than male athletes. Younger female athletes (18-20 years) in comparison with older (24+) may be especially prone to exhibit cognitive symptoms of depression, whereas younger male athletes (18-20) in comparison with older males (27+) may be especially prone to experiencing issues with sleep and appetite. Our study also shows that when utilizing PHQ-9 cutoff 10 to identify clinically significant depressive symptoms, almost $40 \%$ of the identified cases did not exhibit depressed mood or lack of interest. Hence, referring to athletes with clinically significant depressive symptoms as "depressed" athletes could have been misleading in the current study. It is, however, important to underline that $90 \%$ of athletes with clinically significant symptoms reported having experienced at least three different depressive symptoms most of the days in the past 2 weeks. Hence, although some athletes in this group did not experience the core symptoms of depression, they may have, nevertheless, experienced significant distress. With 
these considerations in mind, future studies are encouraged to further explore individual symptoms in addition to sum scores and to explore symptoms in relation to athletes' overall psychosocial functioning.

\section{Note}

1. When we report the overall prevalence of each symptom (see Table 2), a score $\geq 2$ was used to identify symptom presence for all symptoms.

\section{References}

American Psychiatric Association. (2013). Diagnostic and statistical manual of mental disorders $\left(D S M-5^{\circledR}\right)$. Washington, DC: Author. doi:10.1176/appi.books. 9780890425596

Beable, S., Fulcher, M., Lee, A.C., \& Hamilton, B. (2017). SHARPSports mental health awareness research project: Prevalence and risk factors of depressive symptoms and life stress in elite athletes. Journal of Science \& Medicine in Sport, 20(12), 1047-1052. PubMed ID: 28601589 doi:10.1016/j.jsams.2017.04.018

Bell, K.R., Vargas, B.B., Wilmoth, K., Didehbani, N., Godbey, E., Paliotta, C., \& Cullum, M. (2016). Poster 265 relationship between severe headache and elevated depression and anxiety scores after sports-related concussion. 2016 AAPM\&R Annual Assembly Abstracts, 8(9, Supplement), S246. doi:10.1016/j.pmrj.2016.07.438

Birrer, D., Lienhard, D., Williams, C.A., Röthlin, P., \& Morgan, G. (2013). Prevalence of non-functional overreaching and the overtraining syndrome in Swiss elite athletes. Schweiz Z Sportmedizin Sporttraumatol, 61, 23-29.

Breslau, J., Gilman, S.E., Stein, B.D., Ruder, T., Gmelin, T., \& Miller, E. (2017). Sex differences in recent first-onset depression in an epidemiological sample of adolescents. Translational Psychiatry, 7(5), e1139-e1139. PubMed ID: 28556831 doi:10. 1038/tp.2017.105

Brewer, B.W., \& Petitpas, A.J. (2017). Athletic identity foreclosure. Current Opinion in Psychology, 16, 118-122. PubMed ID: 28813333 doi:10.1016/j.copsyc.2017.05.004

Caroleo, M., Carbone, E.A., Primerano, A., Foti, D., Brunetti, A., \& Segura-Garcia, C. (2019). The role of hormonal, metabolic and inflammatory biomarkers on sleep and appetite in drug free patients with major depression: A systematic review. Journal of Affective Disorders, 250, 249-259. PubMed ID: 30870775 doi:10.1016/j.jad.2019. 03.015

Doherty, S., Hannigan, B., \& Campbell, M.J. (2016). The experience of depression during the careers of elite male athletes. Frontiers in Psychology, 7, 1069-106. doi:10.3389/ fpsyg.2016.01069

Donohue, B., Galante, M., Maietta, J., Lee, B., Paul, N., Perry, J.E., .. Allen, D.N. (2019). Empirical development of a screening method to assist mental health referrals in collegiate athletes. Journal of Clinical Sport Psychology, 13(4), 561-579. doi:10.1123/ jcsp.2018-0070

Donohue, B., Gavrilova, Y., Galante, M., Gavrilova, E., Loughran, T., Scott, T., ... Allen, D.N. (2018). Controlled evaluation of an optimization approach to mental health and sport performance. Journal of Clinical Sport Psychology, 12(2), 234-267. doi:10. 1123/jcsp.2017-0054

Du Preez, E.J., Graham, K.S., Gan, T.Y., Moses, B., Ball, C., \& Kuah, D.E. (2017). Depression, Anxiety, and Alcohol Use in Elite Rugby League Players Over a Competitive Season. Clinical Journal of Sport Medicine, 27(6), 530-535. doi:10. 1097/JSM.0000000000000411 
Fried, E.I., Epskamp, S., Nesse, R.M., Tuerlinckx, F., \& Borsboom, D. (2016). What are 'good' depression symptoms? Comparing the centrality of DSM and non-DSM symptoms of depression in a network analysis. Journal of Affective Disorders, 189, 314-320. PubMed ID: 26458184 doi:10.1016/j.jad.2015.09.005

Fried, E.I., \& Nesse, R.M. (2014). The impact of individual depressive symptoms on impairment of psychosocial functioning. PLoS One, 9(2), e90311. PubMed ID: 24587318 doi:10.1371/journal.pone.0090311

Fried, E.I., \& Nesse, R.M. (2015a). Depression is not a consistent syndrome: An investigation of unique symptom patterns in the STAR* D study. Journal of Affective Disorders, 172, 96-102. doi:10.1016/j.jad.2014.10.010

Fried, E.I., \& Nesse, R.M. (2015b). Depression sum-scores don't add up: Why analyzing specific depression symptoms is essential. BMC Medicine, 13(1), 72. doi:10.1186/ s12916-015-0325-4

Fried, E.I., Nesse, R.M., Zivin, K., Guille, C., \& Sen, S. (2014). Depression is more than the sum score of its parts: Individual DSM symptoms have different risk factors. Psychological Medicine, 44(10), 2067-2076. PubMed ID: 24289852 doi:10.1017/ S0033291713002900

Gerber, M., Best, S., Meerstetter, F., Walter, M., Ludyga, S., Brand, S., .. Gustafsson, H. (2018). Effects of stress and mental toughness on burnout and depressive symptoms: A prospective study with young elite athletes. Journal of Science and Medicine in Sport. doi:10.1016/j.jsams.2018.05.018

Golding, L., Gillingham, R.G., \& Perera, N.K.P. (2020). The prevalence of depressive symptoms in high-performance athletes: A systematic review. The Physician and Sportsmedicine, 48(3), 247-258. doi:10.1080/00913847.2020.1713708

Gorczynski, P.F., Coyle, M., \& Gibson, K. (2017). Depressive symptoms in high-performance athletes and non-athletes: A comparative meta-analysis. British Journal Of Sports Medicine, 51(18), 1348-1354. PubMed ID: 28254747 doi:10.1136/bjsports-2016-096455

Hammond, T., Gialloreto, C., Kubas, H., \& Hap Davis, H., 4th. (2013). The prevalence of failure-based depression among elite athletes. Clinical Journal Of Sport Medicine: Official Journal Of The Canadian Academy Of Sport Medicine, 23(4), 273-277. doi:10.1097/JSM.0b013e318287b870

Hankin, B.L., Abramson, L.Y., Moffitt, T.E., Silva, P.A., McGee, R., \& Angell, K.E. (1998). Development of depression from preadolescence to young adulthood: Emerging gender differences in a 10-year longitudinal study. Journal of Abnormal Psychology, 107(1), 128. PubMed ID: 9505045 doi:10.1037/0021-843X.107.1.128

He, C., Levis, B., Riehm, K.E., Saadat, N., Levis, A.W., Azar, M., . . Sun, Y. (2020). The Accuracy of the patient health questionnaire-9 algorithm for screening to detect major depression: An individual participant data meta-analysis. Psychotherapy and Psychosomatics, 89(1), 25-37. PubMed ID: 31593971 doi:10.1159/000502294

Ingram, R.E., Siegle, G.J., \& Steidtmann, D. (2015). Methodological issues in the study of depression. In I.H. Gotlib \& C.L. Hammen (Eds.), Handbook of depression (3rd ed., pp. 45-63). New York, NY: The Guilford Press.

Joffres, M., Jaramillo, A., Dickinson, J., Lewin, G., Pottie, K., Shaw, E., ... Tonelli, M. (2013). Recommendations on screening for depression in adults. Canadian Medical Association Journal, 185(9), 775. PubMed ID: 23670157 doi:10.1503/ cmaj.130403

Junge, A., \& Feddermann-Demont, N. (2016). Prevalence of depression and anxiety in toplevel male and female football players. BMJ Open Sport \& Exercise Medicine, 2(1), e000087. PubMed ID: 27900164 doi:10.1136/bmjsem-2015-000087

Junge, A., \& Prinz, B. (2019). Depression and anxiety symptoms in 17 teams of female football players including 10 German first league teams. British Journal Of Sports Medicine, 53(8), 471-477. PubMed ID: 29420239 doi:10.1136/bjsports-2017-098033 
Kreher, J.B. (2016). Diagnosis and prevention of overtraining syndrome: An opinion on education strategies. Open Access Journal of Sports Medicine, 7, 115. PubMed ID: 27660501 doi:10.2147/OAJSM.S91657

Kristjánsdóttir, H., Sigurðardóttir, P., Jónsdóttir, S., Porsteinsdóttir, G., \& Saavedra, J. (2019). Body image concern and eating disorder symptoms among elite Icelandic athletes. International Journal of Environmental Research and Public Health, 16(15), 2728. doi:10.3390/ijerph16152728

Kroenke, K., \& Spitzer, R.L. (2002). The PHQ-9: A new depression diagnostic and severity measure. Psychiatric Annals, 32(9), 509-515. doi:10.3928/0048-5713-20020901-06

Kroenke, K., Spitzer, R.L., \& Williams, J.B. (2001). The PHQ-9: Validity of a brief depression severity measure. Journal of General Internal Medicine, 16(9), 606-613. PubMed ID: 11556941 doi:10.1046/j.1525-1497.2001.016009606.x

Kroshus, E. (2016). Variability in institutional screening practices related to collegiate student-athlete mental health. Journal Of Athletic Training, 51(5), 389-397. PubMed ID: 27111587 doi:10.4085/1062-6050-51.5.07

Küttel, A., \& Larsen, C.H. (2019). Risk and protective factors for mental health in elite athletes: A scoping review. International Review of Sport and Exercise Psychology, 13(1), 231-265. doi:10.1080/1750984x.2019.1689574

Levis, B., Benedetti, A., Ioannidis, J.P., Sun, Y., Negeri, Z., He, C., . . Neupane, D. (2020). Patient Health Questionnaire-9 scores do not accurately estimate depression prevalence: Individual participant data meta-analysis. Journal of Clinical Epidemiology, 112, 115-128. doi:10.1016/j.jclinepi.2020.02.002

Lux, V., \& Kendler, K.S. (2010). Deconstructing major depression: A validation study of the DSM-IV symptomatic criteria. Psychological Medicine, 40(10), 1679. PubMed ID: 20059797 doi:10.1017/S0033291709992157

Manea, L., Gilbody, S., \& McMillan, D. (2012). Optimal cut-off score for diagnosing depression with the patient health questionnaire (PHQ-9): A meta-analysis. Canadian Medical Association Journal, 184(3), E191-E196. PubMed ID: 22184363 doi:10. 1503/cmaj.110829

Manea, L., Gilbody, S., \& McMillan, D. (2015). A diagnostic meta-analysis of the Patient Health Questionnaire-9 (PHQ-9) algorithm scoring method as a screen for depression. General Hospital Psychiatry, 37(1), 67-75. PubMed ID: 25439733 doi:10.1016/j. genhosppsych.2014.09.009

Martin, A., Rief, W., Klaiberg, A., \& Braehler, E. (2006). Validity of the brief patient health questionnaire mood scale (PHQ-9) in the general population. General Hospital Psychiatry, 28(1), 71-77. PubMed ID: 16377369 doi:10.1016/j.genhosppsych.2005.07.003

Matos, N.F., Winsley, R.J., \& Williams, C.A. (2011). Prevalence of nonfunctional overreaching/overtraining in young English athletes. Medicine \& Science in Sports \& Exercise, 43(7), 1287-1294. doi:10.1249/MSS.0b013e318207f87b

McGuire, L.C., Ingram, Y.M., Sachs, M.L., \& Tierney, R.T. (2017). Temporal changes in depression symptoms in male and female collegiate student-athletes. Journal of Clinical Sport Psychology, 11(4), 337-351. doi:10.1123/JCSP.2016-0035

Moesch, K., Kenttä, G., Kleinert, J., Quignon-Fleuret, C., Cecil, S., \& Bertollo, M. (2018). FEPSAC position statement: Mental health disorders in elite athletes and models of service provision. Psychology of Sport and Exercise, 38, 61-71. doi:10.1016/j. psychsport.2018.05.013

Mojtabai, R. (2017). Universal depression screening to improve depression outcomes in primary care: Sounds good, but where is the evidence? Psychiatric Services, 68(7), 724-726. PubMed ID: 28292224 doi:10.1176/appi.ps.201600320

Moriarity, D., \& Alloy, L.B. (2020). Beyond diagnoses and total symptom scores: Diversifying the level of analysis in psychoneuroimmunology research. Brain, Behavior, and Immunity, 89, 1-2. doi:10.1016/j.bbi.2020.07.002 
Mummery, K. (2005). Essay: Depression in sport. Lancet, 366, S36-S37. PubMed ID: 16360745 doi:10.1016/S0140-6736(05)67840-3

Nixdorf, I., Beckmann, J., \& Nixdorf, R. (2020). Psychological predictors for depression and burnout among German junior elite athletes. Frontiers in Psychology, 11, 601, 1-13. doi:10.3389/fpsyg.2020.00601

Nixdorf, I., Frank, R., \& Beckmann, J. (2016). Comparison of athletes' proneness to depressive symptoms in individual and team sports: Research on psychological mediators in junior elite athletes. Frontiers in Psychology, 7, 8. doi:10.3389/fpsyg.2016.00893

Nixdorf, I., Hautzinger, M., \& Beckmann, J. (2013). Prevalence of depressive symptoms and correlating variables among German elite athletes. Journal of Clinical Sport Psychology, 7(4), 313-326. doi:10.1123/jesp.7.4.313

Pálsdóttir, V.E. (2007). Réttmati sjálfsmatskvarðans Patient Health Questionnaire (PHQ) gagnvart geðgreiningarviðtalinu Mini International Neuropsychiatric Interview (MINI) við að greina geðraskanir hjá heilsugaslusjúklingum (An unpublished Cand. Psych dissertation). University of Iceland.

Peluso, M.A.M., \& Andrade, L.H.S.G.de. (2005). Physical activity and mental health: The association between exercise and mood. Clinics, 60(1), 61-70. doi:10.1590/S180759322005000100012

Purcell, R., Gwyther, K., \& Rice, S.M. (2019). Mental health in elite athletes: Increased awareness requires an early intervention framework to respond to athlete needs. Sports Medicine-Open, 5(1), 46. PubMed ID: 31781988 doi:10.1186/s40798-019-0220-1

Radloff, L.S. (1977). The CES-D scale: A self-report depression scale for research in the general population. Applied Psychological Measurement, 1(3), 385-401. doi:10.1177/ 014662167700100306

Reardon, C.L., Hainline, B., Aron, C.M., Baron, D., Baum, A.L., Bindra, A., . . Currie, A. (2019). Mental health in elite athletes: International Olympic Committee consensus statement (2019). British Journal of Sports Medicine, 53(11), 667-699. PubMed ID: 31097450 doi:10.1136/bjsports-2019-100715

Rice, S.M., Purcell, R., De Silva, S., Mawren, D., McGorry, P.D., \& Parker, A.G. (2016). The mental health of elite athletes: A narrative systematic review. Sports Medicine (Auckland, N.Z.), 46(9), 1333-1353. doi:10.1007/s40279-016-0492-2

Ringland, A. (2016). Commentary: The experience of depression during the careers of elite male athletes. Frontiers in Psychology, 7, 2. doi:10.3389/fpsyg.2016.01869

Roberts, C.-M., Faull, A.L., \& Tod, D. (2016). Blurred lines: Performance enhancement, common mental disorders and referral in the UK athletic population. Frontiers in Psychology, 7, 1067. PubMed ID: 27468273 doi:10.3389/fpsyg.2016.01067

Schaal, K., Tafflet, M., Nassif, H., Thibault, V., Pichard, C., Alcotte, M., . . . Toussaint, J.-F. (2011). Psychological balance in high level athletes: Gender-based differences and sport-specific patterns. PloS One, 6(5), e19007-e19007. PubMed ID: 21573222 doi:10.1371/journal.pone.0019007

Schuch, F.B. (2015). Depression in athletes or increased depressive symptoms in athletes? Current Sports Medicine Reports, 14(3), 244-244. PubMed ID: 25968859 doi:10. 1249/JSR.0000000000000151

Silva-Rocha, V.V., de Sousa, D.A., \& Osório, F.L. (2019). psychometric properties of the Brazilian version of the sport anxiety scale-2. Frontiers In Psychology, 10, 806-806. PubMed ID: 31040807 doi:10.3389/fpsyg.2019.00806

Tahtinen, R., \& Kristjansdottir, H. (2019). The influence of anxiety and depression symptoms on help-seeking intentions in individual sport athletes and non-athletes: The role of gender and athlete status. Journal of Clinical Sport Psychology, 13(1), 134-151. doi:10.1123/jcsp.2017-0028

Tahtinen, R., McDougall, M., Feddersen, N., Tikkanen, O., Morris, R., \& Ronkainen, N.J. (2020). Me, myself, and my thoughts: The influence of brooding and reflective 
rumination on depressive symptoms in athletes in the United Kingdom. Journal of Clinical Sport Psychology, 14(3), 285-304. doi:10.1123/jcsp.2019-0039

Trojian, T. (2016). Depression is under-recognised in the sport setting: Time for primary care sports medicine to be proactive and screen widely for depression symptoms. British Journal of Sports Medicine, 50(3), 137-139. PubMed ID: 26614764 doi:10. 1136/bjsports-2015-095582

Weber, S., Puta, C., Lesinski, M., Gabriel, B., Steidten, T., Bär, K.-J., .. . Gabriel, H.H.W. (2018). Symptoms of Anxiety and Depression in Young Athletes Using the Hospital Anxiety and Depression Scale. Frontiers In Physiology, 9, 182-182. PubMed ID: 29563884 doi:10.3389/fphys.2018.00182

Wolanin, A., Gross, M., \& Hong, E. (2015). Depression in athletes: Prevalence and risk factors. Current Sports Medicine Reports, 14(1), 56-60. PubMed ID: 25574886 doi:10.1249/JSR.0000000000000123

Wolanin, A., Hong, E., Marks, D., Panchoo, K., \& Gross, M. (2016). Prevalence of clinically elevated depressive symptoms in college athletes and differences by gender and sport. British Journal Of Sports Medicine, 50(3), 167-171. PubMed ID: 26782764 doi:10.1136/bjsports-2015-095756

Zimmerman, M., Ellison, W., Young, D., Chelminski, I., \& Dalrymple, K. (2015). How many different ways do patients meet the diagnostic criteria for major depressive disorder? Comprehensive Psychiatry, 56, 29-34. PubMed ID: 25266848 doi:10.1016/ j.comppsych.2014.09.007 